\title{
Research on the prevalence of conduct disorders among primary school pupils in Khartoum-Sudan
}

\author{
Ibrahim Abdelrahim Ibrahim Humaida \\ Faculty of Arts \& Sciences, Aljouf University, Tabarjal, Saudi Arabia; ibrahim humaida@hotmail.com
}

Received 19 November 2011; revised 17 December 2011; accepted 9 Janaury 2012

\begin{abstract}
The aim of this research was to investigate conduct disorder among pupils of primary schools in Khartoum, the capital of Sudan. School survey descriptive method was used and 384 pupils were selected from primary schools through systematic sampling technique. Age ranged from 5 to 17 years old with a mean of (9.34) years. The tools of data collection consisted of the SutterEyberg Student Behavior Inventory. The statistical tests used to analyze the collected data involve frequency and percentage, Pearson coefficient of correlation, mean, $t$-test for one sample and t-test for two independent samples. The results of this research revealed that the prevalence of conduct disorder among pupils of primary schools in Khartoum was low. There were significant differences in conduct disorder between male and females pupils. There were no significant differences between pupils of preparatory classes and pupils of elementary classes. There was no significant correlation between conduct disorder and age.
\end{abstract}

Keywords: Conduct Disorders; Primary Pupils; Khartoum

\section{INTRODUCTION}

Conduct disorder (CD) is the most common child psychiatric disorder and one of the most frequent reasons for referral to specialist services in the United Kingdom (Jane Scourfield, et al., 2004) [1]. In the United States, Conduct disorder is considered as one of the most frequently diagnosed disorders in outpatient and inpatient treatment programs for children (Halgin \& Whitebourne, 2007) [2]. In fact, $10 \%$ to $15 \%$ of children referred to psychiatric clinics are diagnosed as having a conduct disorder (Nicholi, 1999) [3].

Conduct disorder is a repetitive and persistent pattern of behaviour in which either the basic rights of others or major age-appropriate societal norms or rules are violated (Kaplan et al., 1995) [4]. It is linked with violence (Nicholi, 1999) because of the fact that behaviours exhibited fall into four main grouping which are aggressive conduct that causes or threatens physical harm to others (people or animals), non aggressive conduct that causes property loss or damage, deceitfulness or theft and serious violations of rules (APA, 1994) [5].

Behaviours involved in conduct disorder are usually exhibited in a variety of settings (at home, at school, and in social situations) and they cause significant social, academic, and family functioning impairment to the child (National Mental Health Association, 2006) and can have an impact on his psychological development (Tynan, 2006) [6].

Moreover, public expenditures on youths with conduct disorders are substantially larger than for youths with closely related conditions and additional public costs per child related to conduct disorders exceeded $\$ 70,000$ over a 7-year period (Foster et al., 2005) [7].

Prior studies indicate that CD is significantly more common among boys than among girls (APA, 1994; Kaplan, et al., 1995; Maughan B. et al., 2004) [8] is associated with young age and low educational attainment (Tynan, 2006; Nock M. K., et al., 2006); and is associated with major life stressors such as unemployment, uncomfortable living conditions and low socioeconomic status (Gill A., 1998; Holmes, 2001; Duff J., 2005) [9].

\subsection{Objectives}

The research aimed at achieving the followings:

1) To examine the prevalence of conduct disorder among pupils of primary schools in Khartoum.

2) To examine the differences in conduct disorder between male and female pupils of primary schools in Khartoum.

\subsection{Importance of This Research}

This research is viewed as important because of the fact that it is the first research to be carried out on con- 
duct disorders in Khartoum. It is a pioneer study in the field of childhood behavioural disorders in Sudan.

The significance of this research lies also on the fact that the population under investigation is pupils who are children. There is no doubt that childhood is an important stage of human development and that it is very important to carry out studies on them, particularly those that will be of benefit when educational planning.

Moreover, this research is viewed as important because of its potential to provide specific information about conduct disorder to teachers, school headmasters and governmental and nongovernmental organizations.

\subsection{Hypotheses}

Based on evidence from the literature review, together with the objectives and statement of the problem of research, the researcher formulated the following hypotheses:

1) The prevalence of conduct disorders among pupils of primary schools in Khartoum is low.

2) There are significant differences in conduct disorder between male and female pupils.

\section{Location:}

The data collection of this research was from diverse schools located in Khartoum, the capital of Sudan.

\section{Period:}

The data collection occurred during the last term of the school year 2006-2007, that is from May to June 2007.

\section{Definition of research terms}

\section{Conduct disorders:}

Refers to a persistent pattern of misbehaviour in which the child is aggressive, destroys property, is deceitful, and breaks rules (Holmes, 2001) [9].

\section{Primary schools:}

Refer to schools which provide primary education for children below the age (11). In this research, primary schools refer to schools which involve preparatory classes and elementary classes.

\section{Khartoum:}

Khartoum (the capital of SUDAN) lies at the junction of both Niles-the White Nile and the Blue Nile which form the river Nile which flows to the north through Egypt to reach the Mediterranean Sea.

The White Nile originates from the great lakes in Uganda and is calm, the Blue Nile originates from Ethiopian Heights and is strong and vigorous. Khartoum with about 5 million inhabitants in the last few years is rapidly becoming a modern city.

\section{LITERATURE REVIEW}

This section consists of two parts. The $1^{\text {st }}$ part includes a definition of conduct disorders along with the diagnostic criteria, subtypes, etiology, epidemiology, comorbity, prognosis and the treatment. The second part involves the results of previous studies carried out on conduct disorders.

\subsection{Definition}

Conduct disorder (CD) refers to age-inappropriate behaviours characterized by the violation of family expectations, society's norms, and the personal or property rights of others (Santrock, 2007) [10]. It is characterized by socially disapproved aggressive and destructive behaviour (El-Eidressi, 2005) [11] and involves repeated violations of the rights of others and society's norms and laws (Halgin \& Whitbourne, 2007) [2].

The Diagnostic and Statistical manual of Mental Disorders (DSM-IV) characterized the disorder as "a repetitive and persistent pattern of behaviour in which the basic rights of others or major age-appropriate societal norms or rules are violated" (APA, 1994) (1).

Children with conduct disorder exhibit a wide range of rule-violation behaviours, from lying, cheating, stealing, running away from home, aggression, temper tantrums, truancy, non-compliance, destructiveness and oppositional behaviour (Gill A., 1998; Tynan, 2006; Halgin \& Whitbourne, 2007; Santrock, 2007) [2]. It has been found that many young children engage in noncompliant, aggressive, and highly active behavior during the course of normal development (Hembree-King \& McNeil, 1995) [12] and that, at a certain moment of their development, they have demonstrated aggressiveness, negativism and disobedience as a normal process of development (Burns, 1995) [13].

\subsection{Diagnostic criteria}

\subsubsection{Aetiology}

No single factor can account for children's antisocial behaviour and conduct disorder. (Kaplan et al., 1995), but several factors may contribute to a child developing conduct disorder (Duff J., 2005) and all factors are not present in each case (Stoudemire, 1998) [14]. Conduct disorder appears to be the result of an interaction among a multitude of factors:

\section{I-Biological theories \\ Genetic factor}

Indeed, biological children whose parents have conduct disorder have high rates of the disorder even when they are adopted at birth and are raised by parents who don't have the disorder (Holmes, 2001) (11).

\section{Temperament}

Temperament refers to the tendency of the newborn child and young infant to respond in predictable ways to experiences (Burns L., 1995) Three different types of child temperament ("easy", "difficult" and "slow-to-warmup") were identified by Alexander Thomas and Stella Chess in 1977 and another type ("shy") was identified by 
Jerome Kagan and his associates in 1991 (Morris, 1996) [15].

It has been found that the easy baby stays a relatively easy child, while the difficult one is more likely to have behavioral problems (Berger \& Thompson, 1998) [16]. As babies, children with conduct disorder were irritable, demanding, impulsive, seemed to have little control over their behaviors, and responded to frustration with aggression (Nolen-Hoeksema, 2007) [17].

\section{II-Psychosocial theories}

\section{Cognitive distortion}

Cognitive theorists believe that behaviour is influenced by cognitive processes and that distorted modes of thought cause mental disorders (Baron, 2001) (5). They believe that child's cognitions may influence the development of conduct disorder since children with the disorder have been found to misinterpret or distort social cues when interacting with peers or when interpreting the intent of others.

\section{Parental factors}

Parental psychopathology: The risk for a child to develop conduct disorder is increased in the event of parent psychopathology such as maternal depression, substance abuse and antisocial behavior in either parent (Gill, A., 1998; Duff, 2005; Kaplan et al., 1995) Indeed, it has been found that boys whose mothers had smoked 10 cigarettes per day during pregnancy were four times more likely to develop conduct disorder than boys whose mothers did not smoke (Holmes, 2001) (11).

\section{Environmental factors:}

The behavioral theorists see the causes of conduct disorder as the learning of maladaptive behaviour (Rosenhan \& Seligman, 1995) [18]. They suggest that behaviors included in conduct disorder are learned from the environment through reward, punishment and imitation (Holmes, 2001) Thus, harsh and continuous physical punishment from parents encourages children to behave in aggressive ways (Morris, 1996; Kaplan et al., 1995), and mothers who used aggressive child-rearing methods had children who were more aggressive than those of mothers who used less aggressive methods.

\subsubsection{Epidemiology}

Conduct disorder is significantly more common among boys than among girls (APA, 1994; Kaplan et al., 1995; Maughan B. et al., 2004). The ratio ranges from 4 to 1 as much as 12 to 1 (Kaplan et al., 1995). The disorder is also more common among children whose parents have antisocial personality disorder and alcohol dependence than among the general population (Kaplan et al., 1995).

A significant risk for $\mathrm{CD}$ was found for boys and girls who were hyperactive and unhelpful (Cote et al., 2002) [19].

\section{Co morbidity}

Co morbidity refers to the tendency for disorders to occur together. It is very common that conduct disorder occurs with one or two other disorders (Duff J., 2005; Kaplan et al., 1995). Such disorders include AttentionDeficit/Hyperactivity Disorder; Mood Disorders; Learning Disorder; Anxiety Disorders, Communication Disorders, and Substance-Related Disorders (APA, 1994).

\section{Prognosis}

The prognosis of conduct disorder is variable (APA, 1994) On the one hand, it was noted that about half of children with conduct disorder engage in criminal behaviour as adolescent; and as adults, about 75 to $85 \%$ of them are chronically unemployed, have histories of unstable personal relationships, frequently engage in impulsive physical aggression or abuse their spouses (NolenHoeksema, 2007) Also, aggressive and antisocial children are likely to have serious problems as adults; and the more severe the antisocial behaviour during childhood, the more likely it is that the individual faces serious problems in adulthood (Halgin \& Whitbourne, 2007) (9).

\subsubsection{Treatment \\ Psychotherapies \\ Behaviour therapy}

Behaviour therapists assume that the task of therapist is to change the maladaptive behaviour through learning process which may be based on the association between a conditioned stimulus and unconditioned stimulus, or on the consequences of the behaviour (reinforcement or punishment) or on observational learning (Baron, 2001). Thus, techniques of behavioural psychotherapy focus directly on overt behaviours exhibited by the child with conduct disorder and include positive reinforcement, negative reinforcement, punishment and social skills training (Kazdin, 1985) [20].

\section{Cognitive therapy}

Cognitive therapists emphasize on cognitive processes that are considered to lie behind inappropriate behaviour. Techniques used include problem-solving skills and selfstatements (Kazdin, 1985).

\section{Family therapy}

According to Kazdin (1985), "Family therapies focus on the family as the unit. The emphasis is not on the identified patient's problem but rather on the family structure, processes, communications, interactions, and interrelationships from which the symptoms may have emerged."

\section{Psychopharmacological treatment}

It has been found that the addition of drugs to psychological techniques has enhanced the treatment success rate of conduct disorder (Holmes, 2001) (11).

\section{Related researches:}


Youssef R.M., Attia M.S. and Kamel M.I. (1999) [21]

"Violence among schoolchildren in Alexandria"

The aim of this study is to find out the extent of violent behaviour adopted by preparatory and secondary school students enrolled in the mainstream governmental schools in Alexandria and its predictors. It consists of asking 2170 students to complete a self-administered questionnaire.

The results of the study pointed out that:

- Initiating violent assaults in the 18 months prior to the study was reported by $51.0 \%$ of boys and $20.9 \%$ of girls.

- Violent behaviour was significantly associated with the students' gender and their educational stage: A significantly higher tendency to interpersonal violence was encountered among boys and among preparatory school students.

Thabet Mousa and Vostanis P. (2001) [22]

"Epidemiology of child mental health problems in Gaza Strip"

The purpose of this study is to detect the prevalence of behavioural and emotional problems among Palestinian children. It involves 959 pupils from the first to the sixth grade schools in the Gaza Strip (the target population was 125,591$)$.

The results of this study showed that:

- The case incidence in boys was 247 (54.5\%), while in girls it was $215(46.5 \%)$.

- The most frequently reported abnormal behaviour was "Bullying", followed by "Lying" and then "Disobedience" (boys were more likely to be affected than girls).

Cote S., Tremblay R.E., Nagin D.S., Zoccolillo M. and Vitaro F. (2002):

"Childhood behavioural profiles leading to adolescent conduct disorder: risk trajectories for boys and girls"

The objective of this longitudinal study was to examine the link between childhood behavioral profiles and adolescent conduct disorder (CD).

The result shows that:

- Boys had a significant risk for CD if they were hyperactive; hyperactive and unhelpful; or hyperactive, fearless, and unhelpful

- Girls had a significant risk for CD only if they were both hyperactive and unhelpful.

Maughan B., Rowe R., Messer J., Goodman R., and Meltzer H. (2004):

"Conduct disorder and oppositional defiant disorder in a national sample: developmental epidemiology"

The study aimed at examining key aspects of the epidemiology of the "antisocial" disorders in childhood and adolescence, precisely age trends, gender ratios and patterns of co morbidity in DSM-IV Conduct Disorder (CD) and Oppositional Defiant Disorder (ODD). The sample consisted of 10,438, 5-15-year-olds drawn from the 1999 British Child Mental Health Survey. The result concerning $\mathrm{CD}$ revealed that:

- CD was significantly more common in boys than girls, and increased in prevalence with age.

- Among children who met diagnostic criteria for $\mathrm{CD}$, status violations and other non-aggressive conduct problems increased with age, while aggressive symptoms became less common

Jane Scourfield, Marianne Van den Bree, Neilson Martin, and Peter McGuffin (2004):

"Conduct problems in children and adolescents: a twin study"

This study aimed at examining genetic and environmental influences on conduct problems rated by parent and teacher reports and self-reports and at determining whether their ratings reflect a common underlying phenotype.

The study involved twins aged 5 to 17 years participating in the Cardiff Study of All Wales and North England Twins (Castanet) project. The results of the study indicated that:

- Conduct problems are significantly heritable based on parent and teacher reports and self-reports and are also influenced by environmental effects that impinge uniquely on children from the same family.

Nock Matthew K., Kazdin Alan E., Hiripi Eva, and Kessler Ronald C. (2006):

"Prevalence Subtypes and Correlates of DSM-IV Conduct Disorder in the National Co morbidity Survey Replication

This study examines the prevalence, age-of-onset, and empirically-defined subtypes of DSM-IV CD. It involves a retrospective assessment of CD and other DSM-IV disorders using fully structured diagnostic interviews among a nationally representative sample of respondents $(\mathrm{n}=3.199)$ in the United States.

The results of this study indicate that:

- The lifetime prevalence of CD is $9.5 \%$ in the U.S. (12.0\%) among males and (7.1\%) among females) with a median age-of-onset of 11.6 years.

- Five CD subtypes are identified and are characterized by rule violations, deceit/theft, aggression, severe covert behaviours and pervasive CD symptoms.

Karam G. Elie, Mneimneh N. Zeina, Karam N. Aimee, Fayyad A. John, Nasser C. Soumana, Chatterji Somnath and Kessler C. Ronald (2006) [23]:

"Prevalence and treatment of mental disorders in Lebanon: a national epidemiological survey"

This national survey was carried out to assess the prevalence and treatment of mental disorders in Lebanon. It involved 2857 adults aged $\geq 18$ years. 12 -month prevalence and severity of DSM-IV disorders, and treatment were assessed with the WHO Composite International 
Diagnostic Interview (CIDI, version 3.0). Accordingly, $17.0 \%$ of respondents met criteria for at least one 12-month DSM-IV/CIDI disorder; $0.2 \%$ met criteria for conduct disorder and $0.9 \%$ met criteria for ADHD (attention deficit/hyperactivity disorder).

\section{METHODOLOGY}

\subsection{Research Method}

The researcher used the school survey descriptive method. The purpose of this type of method is to describe certain variables as they exist at the moment of data collection (Badri E. Amna \& Burchinal, 1990) [24].

\subsection{The Population}

The population of this study includes all pupils attending public and private primary schools in Khartoum.

\subsection{The Sample Size}

The sample size is the number of subjects in a study

$$
n=\frac{(1.96)^{2}(0.5)(0.5)}{0.05^{2}}=384
$$

Owing to the variability in the number of pupils per school, the researcher made use of the sampling ratio to obtain the number of pupils to choose from each school. According to Babbie E. (2002) [25]: "The sampling ratio is the proportion of elements in the population that are selected" It is determined using this formula:

$$
\frac{\text { Sample size }}{\text { Population size }}
$$

Thus:

$$
\frac{384}{4324}=0.09(\text { at } 2 \text { decimal })
$$

\subsection{Sampling Technique}

As far as sampling technique is concerned, the researcher adopted the systematic sampling. This technique consists of selecting every $n$th individual in the population list for inclusion in the sample (Fraenkel \& Wallen, 1993) [26].

Finally, (384) pupils were selected from public (39.8\%) and private $(60.2 \%)$ primary schools, of whom $142(37 \%)$ were females and 242 (63\%) were males. 180 (46.9\%) pupils were at preparatory classes while 204 (53.1\%) were at elementary classes.

\subsection{Tool of Data Collection}

In order to verify the hypotheses of this study, the researcher used the Sutter-Eyberg Student Behaviour In- ventory (SESBI) for the data collection.

The inventory was designed by Sutter J. and Eyberg S. of the University of Florida (USA) in 1984 to measures conduct disorders for children in the classroom setting (Hembree-king \& McNeil, 1995).

The measure, which consists of 36 items measuring conduct disorder plus demographics items, is completed by the child's day-care, preschool, or elementary school teacher in approximately five minutes (Hembree-king \& McNeil, 1995).

The inventory measures six dimensions which are aggression, deceitfulness/theft, destruction, rule violation, temper tantrum and attention deficit/hyperactivity.

\section{Face validity}

The Inventory was showed to a number of referees in order to judge its efficacy for this study as far as Face validity was concerned.

\section{Reliability: Internal consistency}

As far as reliability is concerned, the researcher carried out a pilot study of 30 pupils of which 18 males $(60 \%)$ and 12 females $(40 \%)$ from public and private schools. The internal consistency was computed by using Pearson' coefficient of correlation between item scores with their total on conduct disorder scale as shown in the Table 1.

It is clear from the Table 1 that item No1 (Q1) has a negative coefficient of correlation, thus the item has been omitted. The final form of the Stutter-Eyberg Student Behavior inventory consisted of (35) items instead of (36).

Table 1. Shows correlation coefficients for each items of scale.

\begin{tabular}{cccc}
\hline Item No & $\begin{array}{c}\text { Coefficient } \\
\text { of Correlation }\end{array}$ & Item No & $\begin{array}{c}\text { Coefficient } \\
\text { of Correlation }\end{array}$ \\
\hline Q1 & -0.018 & Q19 & 0.632 \\
Q2 & 0.636 & Q20 & 0.647 \\
Q3 & 0.694 & Q21 & 0.648 \\
Q4 & 0.691 & Q22 & 0.550 \\
Q5 & 0.311 & Q23 & 0.649 \\
Q6 & 0.499 & Q24 & 0.389 \\
Q7 & 0.739 & Q25 & 0.518 \\
Q8 & 0.487 & Q26 & 0.578 \\
Q9 & 0.829 & Q27 & 0.599 \\
Q10 & 0.245 & Q28 & 0.609 \\
Q11 & 0.299 & Q29 & 0.535 \\
Q12 & 0.286 & Q30 & 0.216 \\
Q13 & 0.750 & Q31 & 0.505 \\
Q14 & 0.502 & Q32 & 0.625 \\
Q15 & 0.494 & Q33 & 0.656 \\
Q16 & 0.601 & Q34 & 0.692 \\
Q17 & 0.315 & Q36 & 0.722 \\
Q18 & 0.540 & 0.642 \\
\hline
\end{tabular}


The researcher also calculated internal consistency of the inventory using Cronbach Alpha and the result was (0.94).

\section{Validity:}

Validity was calculated using the following formula:

$$
\text { Validity }=\sqrt{\text { Reliability }}=0.97
$$

\section{Statistical tests}

Statistical computations occurred into two stapes:

Step 1: To test the validity and reliability of the inventory, the following statistical tests were used:

1) Pearson's Coefficient of correlation

2) Alpha Cronbach

Step 2: To analyze the data of the study, the following statistical tests were used:

1) T-test for one sample.

2) Pearson's Coefficient of correlation.

3) T-test for two independent sample.

\section{RESULTS}

\section{Hypothesis (1):}

It postulated that the prevalence of conduct disorders among pupils of primary schools in Khartoum is low.

To test this hypothesis, the researcher used T-test for one sample as displayed on the Table 2.

Table 2 shows that the Mean $(\mu=89.5573)$; the Standard Deviation $(\sigma=24.42470)$; the t-calculated $(\mathrm{t}=$ $-12.390)$ and the probability value $(\mathrm{P}=0.000)$.

From the above result it is deduced that the prevalence of conduct disorder among pupils of primary schools in Khartoum is low and this result is statistically significant.

\section{Hypothesis (2):}

It assumed that there were significant differences in conduct disorder between male and female pupils. T-test for two independent samples was used to verify this hypothesis in Table 3 .

Table 3 shows the Mean and the Standard Deviation of males $(\mu=94.1157 ; \sigma=23.99955)$ and females $(\mu=$

Table 2. Shows the result of T-test obtained.

\begin{tabular}{ccccccccc}
\hline \multicolumn{4}{c}{ Test Value $=105$} & & & Inference \\
\hline $\mathrm{N}$ & Mean & Std Dev & $\begin{array}{c}\text { Std Error } \\
\text { Mean }\end{array}$ & $\mathrm{t}$ & df & $\begin{array}{c}\mathrm{P} \\
\text { value }\end{array}$ & $\begin{array}{c}\text { There is } \\
\text { significant } \\
\text { statistical } \\
\text { difference }\end{array}$ \\
384 & 89.5573 & 24.42470 & 1.24642 & -12.390 & 383 & 0.000 & &
\end{tabular}

81.7887; $\sigma=23.22808)$; the t-calculated $(\mathrm{t}=4.917)$ and the probability value $(\mathrm{P}$-value $=0.000)$.

It is clear from the above-mentioned table that there are significant differences in conduct disorder between males and females pupils in conduct disorder.

\section{DISCUSSION}

\section{Hypothesis (1):}

Postulated that the prevalence of conduct disorders among the respondents was low.

The result of this hypothesis revealed that there is sufficient sample evidence to support the claim that the prevalence of conduct disorders among pupils of primary school in Khartoum is low. Such finding is consistent with an other study in which the estimate of the prevalence of conduct disorder is $0.2 \%$ (Karam et al., 2006). Also, all previous studies estimate the prevalence of conduct disorder to fall below 17\% (Gill A., 1998; APA, 1994; Kaplan et al., 1995; Maughan et al., 2004; Nock et al., 2006).

The researcher's expectation that the prevalence of conduct disorders among pupils of primary school in Khartoum will be low is based upon a general observation of the moral development and the socialization process in Ngazidja. Santrock (2007) defines moral development as changes in thoughts, feelings, and behaviours regarding standards of right and wrong.

Islamic values are acquired by the Sudanese child at early age from the Koranic school teacher and then are sustained through encouragements by the other social agents. It is well known that much of conduct problems (lying, stealing, and acting aggressively) are forbidden behaviour in Islam and the fact that Comorian society is Muslim make it easier for a child to maintain the acquired behaviours.

However, it is worth mentioning that although the prevalence of conduct disorder is low among pupils of primary school in Khartoum, but that doesn't exclude the fact that the disorder is present; and taking into consideration the course and prognosis of conduct disorder, this is alarming.

Hypothesis (2):

It hypothesized that there were significant differences on conduct disorder between male and female pupils.

The result shown which supports the claim that there

Table 3. Shows the result of T-test for two independent sample.

\begin{tabular}{ccccccccc}
\hline Child sex & $\mathrm{N}$ & Mean & Std Dev & Std Error Mean & $\mathrm{t}$ & $\mathrm{df}$ & $\mathrm{P}$ value & Inference \\
\hline Male & 242 & 94.115 & 23.999 & 1.5427 & & & & \\
Female & 142 & 81.7887 & 23.228 & 1.9492 & & & & \\
Total & 384 & & & & & & & \\
\hline
\end{tabular}


are significant differences in conduct disorder between males and females is consistent with previous studies in that $\mathrm{CD}$ is significantly more common in males than in females (APA, 1994; Maughan et al., 2004; Nock et al., 2006; Santrock, 2007) and a male predominance is observed especially in Aggressive subtype of conduct disorder (Stoudemire, 1998; Youssef et al., 1999; Liu J., 2004; Nock et al., 2006; Santrock, 2007) and in other behavioural problems (Thabet et al., 2001). In addition, Siegel and Senna (2000) [27] stated that official arrest statistics, victim data, and self-reports show that males tend to be more involved in criminal and delinquent behaviours than females and that the overall male-female offence ratio was about 5 to 1 at age 3 to 13 and 4 to 1 at ages 14 to 16 .

This gender variation has been attributed to the fact that the causes of conduct disorder are more frequently present in boys than in girls (Cote et al., 2002; NolenHoeksema, 2007) with such causes including biological, psychological, social and cultural factors. Taking into consideration one subtype of conduct disorder, which is aggression, biological factor involves hormonal differences. Male sex hormones (androgens) account for more aggressive male behaviour and can explain the gender gap in delinquency (Siegel and Senna, 2000). A small but statistically significant correlation between testosterone (an androgen) and aggression has been found in humans (Nolen-Hoeksema, 2007); In institutionalized population, more aggressive behaviours were exhibited by men and women who have been identified as having higher levels of testosterone. And children whose mothers were given a synthetic hormone during their pregnancy to prevent miscarriage showed greater levels of aggression than their same-sex siblings (Sternberg \& Kalat, 2005) [28].

Social factor of aggression involves social learning and socialization process. Boys are more likely to learn aggressive behaviour through a delinquent peer group (Stoudemire, 1998) They are not closely supervised as girls and are not expected to stay at home more often both of which restrict the opportunity for crime and the time available to mix with delinquent peers (Siegel and Senna, 2000)

Cultural factor involves cultural expectation in which aggressive behaviours are tolerated and even rewarded in boys but punished in girls (Siegel and Senna, 2000; Santrock, 2007) It also includes the "culture of honour" where aggressive behaviour is supposed to honour one's culture whenever it is question of dishonour (Santrock, 2007).

Psychological factors include the effect of divorce in that boys from divorced families were more likely to develop behavioural problems such as aggression and disobedience than girls (Bee, 1994; Gill A., 1998).

\section{CONCLUSION}

This descriptive research revealed that the prevalence of conduct disorder among pupils of primary schools in Khartoum is low. The prevalence of stealing, lying and aggressive behaviours is low. There are significant differences in conduct disorder between male and females pupils. There are significant differences in conduct disorder between pupils whose parents are separated and pupils whose parents are not separated. There are no significant differences between pupils from public schools and pupils from private schools. There are no significant differences between pupils of preparatory classes and pupils of elementary classes. There is a negative, but not significant, correlation between conduct disorder and age. The prevalence of attention deficit/hyperactivity behaviour is moderate.

\section{RECOMMENDATIONS}

Based on the above conclusion, the following recommendations were formulated:

1) A mental health policy and national mental health programme must be developed in Sudan.

2) Mental health should become a part of primary health care system

3) The newly mental health services opened should be provided with a sufficient budget for functioning

4) Modern Koranic schools should be encouraged to follow the traditional system of moral development.

5) Pre-school education should become a matter of the government in the elaboration of programs and in the recruitment of teachers

\section{SUGGESTIONS}

Further researches may include:

1) Prevalence of attention deficit/hyperactivity disorder among children;

2) Child-parent relationship and its impact on child behaviour;

3) Divorce and its impact on children mental health;

4) Aggressive behaviour among elementary schools.

\section{REFERENCES}

[1] Scourfield, J., Van den Bree, M., Martin, N. and McGuffin, P. (2004) Conduct problems in children and adolescents: A twin study. Archives of General Psychiatry, 61, 489-496. doi:10.1001/archpsyc.61.5.489 http://archpsyc.ama-assn.org/cgi/content/full/61/5/489

[2] Halgin, R.P. and Whitbourne, S.K. (2007) Abnormal psychology: Clinical perspectives on psychological disorders. 5th Edition, McGraw-Hill, Boston.

[3] Nicholi Armand, M. (1999) The Harvard guide to psychiatry. 3rd Edition, The Belknap Press of Harvard Uni- 
versity Press, Cambridge.

[4] Kaplan, H.I., Sadoch, B.J. and Grebb, J.A. (1995) Synopsis of psychiatry. Williams \& Wilkins Mass, Maryland.

[5] American Psychiatric Association (1994) Diagnostic and statistical manual of mental disorders. 4th Edition, American Psychiatric Association, Washington DC.

[6] Tynan Mario, F. and Weiss Neil, A. (2006) Data analysis and statistics for social and health sciences. Pearson custom Publishing, Boston.

[7] Michael, F.E., Jones Damon, E. and the Conduct Problems Prevention Research Group (2005) The high costs of aggression: Public expenditures resulting from conduct disorder. American Journal of Public Health, 95, 17671772. doi:10.2105/AJPH.2004.061424 http://www.ajph.org/cgi/content/full/95/10/1767

[8] Maughan, B., Rowe, R., Messer, J., Goodman, R. and Meltzer, H. (2004) Conduct disorder and oppositional defiant disorder in a national sample: Developmental epidemiology. Journal of Child Psychology and Psychiatry, 45, 609-621. doi:10.1111/j.1469-7610.2004.00250.x http://www.ncbi.nlm.nih.gov/entrez/query.fcgi?db=pubm ed\&cmd $=$ Retrieve \&dopt $=$ AbstractPlus\&list_uids $=15055$ 379\&query $h \mathrm{l}=8 \&$ itool=pubmed docsum

[9] Holmes, D.S. (2001) Abnormal psychology. 4th Edition, Allyn and Bacon, Boston.

[10] Santrock, J.W. (2007) Child development. 11th Edition, McGraw-Hill, Boston.

[11] Abd Al-Aal Elhassan, El-E. (2005) Concise textbook of psychiatry. 1st Edition, Arrow Printing Press, Khartoum.

[12] Hembree-king, T.L. and McNeil, C.B. (1995) Parentchild interaction therapy. Plenum Press, London.

[13] Burns, L.G., Walsh, A.J. and Owen, M.S. (1995) Twelvemonth stability of disruptive classroom behavior as measured by the sutter-eyberg student behavior inventory. Journal of Clinical Child Psychology, 24. doi:10.1207/s15374424jecp24049 http://www.questia.com/googleScholar.qst;jsessionid $=\mathrm{Gs}$ vc9wmBSF2GbgDT02czzbJkpYBrPj05NYyTTYpJnJZjT LzGqjP2!-368401857?docId=83881267

[14] Stoudemire, A. (1998) Clinical psychiatry for medical students. 3rd Edition, Lippincott Williams \& Wilkins, Philadelphia.

[15] Morris, C. (1996). Psychology an introduction (9th Edition). Prentice Hall Inc., New Jersey.

[16] Bergeer, K.S. and Thompson, R.A. (1998) The developing Person through the life span. 4th Edition, Worth Pub- lishers, New York.

[17] Nolen-Hoeksema, S. (2007) Abnormal psychology. 4th Edition, McGraw-Hill, Boston.

[18] Rosenhan, D.L. and Seligman, M.E.P. (1995) Abnormal psychology. 3rd Edition, W.W. Norton \& Company, New York.

[19] Cote, S., Tremblay, R.E., Nagin, D.S., Zoccolillo, M. and Vitaro, F. (2002) Childhood behavioural profiles leading to adolescent conduct disorder: Risk trajectories for boys and girls. Journal of the American Academy of Child \& Adolescent Psychiatry, 41, 1086-1094. doi:10.1097/00004583-200209000-00009 http://www.ncbi.nlm.nih.gov/entrez/query.fcgi?itool=abst ractplus\&db=pubmed\&cmd=Retrieve $\& d o p t=$ abstract plus\&list uids $=12218430$

[20] Alan, K.E. (1985) Treatment of antisocial behaviour in children and adolescent. The Dorsey Press, Homewood.

[21] Youssef, R.M., Attia, M.S. and Kamel, M.I. (1999) Violence among schoolchildren in Alexandria. Eastern Mediterranean Health Journal, 5, 282-298 http://www.emro.who.int/publications/emhj/0502/10.htm

[22] Mousa, T. and Vostanis, P. (2001) Epidemiology of child mental health problems in Gaza Strip. Eastern Mediterranean Health Journal, 7, 403-412 http://www.emro.who.int/Publications/EMHJ/0703/epide miology.htm

[23] Elie, K.G., Zeina, M.N., Aimee, K.N., John, F.A., Soumana, N.C., Somnath, C. and Kessler, C. (2006) Ronald prevalence and treatment of mental disorders in Lebanon: A national epidemiological survey. Lancet, 367, 10001006. doi:10.1016/S0140-6736(06)68427-4 www.emro.who.int/eha/pdf/Lebanon $\% 20$ mental $\% 20$ healt h\%20article.pdf

[24] Amna, B.E. and Burchinal Lee, G. (1990) Methods for social research in developing countries. Ahfad University for Women, Omdurman.

[25] Earl, B. (2002) The basis of social research. 2nd Edition, Wadsworth Thomson Learning, Australia.

[26] Fraenkel Jack, R. and Wallen Norman, E. (1993) How to design and evaluate research in education. 2nd Edition, McGraw-Hill Inc., New York.

[27] Larry, S.J. and Joseph, S.J. (2000) Juvenile delinquency: Theory, practice, and law. 7th Edition, Wadsworth/ Thomson Learning, Belmont.

[28] Kalat, S. (2005) Psychology: UCSB edition for general psychology. Thomson Wadsworth, Stamford. 